\title{
Climate Change: What Are the Implications of Worldview, Political Orientation, Values on Climate Belief and Engagement in the French Context?
}

\author{
Oumar Marega ${ }^{1}$, Philippe Chagnon ${ }^{1}$, Séverine Frère ${ }^{1}$, Anne-Peggy Hellequin ${ }^{2}$, Hervé Flanquart ${ }^{1}$, Iratxe \\ Calvo-Mendieta ${ }^{1}$, Baptiste Berry ${ }^{1} \&$ Sophie Cornet $^{1}$ \\ ${ }^{1}$ Université du Littoral Côte d'Opale, Laboratoire Territoires, Villes, Environnement et Société -TVES, France \\ ${ }^{2}$ Université Paris Nanterre, Laboratoire des Dynamiques Sociales et Recomposition des Espaces- LADYSS, \\ France \\ Correspondence: Oumar Marega, Université du Littoral Côte d'Opale, Laboratoire TVES, Maison de la \\ Recherche en Sciences de l'Homme, 21 quai de la citadelle, BP 35528, 59383 Dunkerque Cedex 1, France. Tel: \\ 33-3-2823-7123. E-mail: oumar.marega@univ-littoral.fr
}

Received: May 29, 2019

doi:10.5539/jsd.v12n4p112
Accepted: June 24, 2019 Online Published: July 30, 2019

URL: https://doi.org/10.5539/jsd.v12n4p112

\begin{abstract}
To what extent do our worldviews, political and religious beliefs and our values influence the way we perceive the climate emergency and the commitment to combat it in France? Through this question we pursue two clear objectives: firstly, to study the social dimensions of climate change and secondly to shed light on the vectors of engagement in the fight against climate change. Based on a perception survey we conducted in the Hauts-de-France region in 2017, we highlight how an approach that takes into account worldview, values and beliefs help us to understand the different attitudes towards CC perception and the fight against it. We show that the opposition between those who are convinced and those who are skeptical about CC refers to ideological differences that are deeply-rooted in the right-left political divide, but also in different beliefs and values. In addition, among the main vectors of climate engagement, our analyses highlight the importance of a worldview based on the finiteness of natural resources, values related to associative engagement and trust.
\end{abstract}

Keywords: adaptation, climate change, engagement, political orientation, values, worldview

\section{Introduction}

The reality of global warming is today the subject of a broad consensus within the scientific community. According to the recent special report of the Intergovernmental Panel on Climate Change (IPCC, 2018), human activities are today considered responsible for a $1.0^{\circ} \mathrm{C}$ increase in the temperature of our planet in comparison with the pre-industrial level. At the current rate of greenhouse gas emissions, this increase could reach $1.5^{\circ} \mathrm{C}$ between 2030 and 2050 . The objective today is to limit global warming to $1.5^{\circ} \mathrm{C}$, to give people and ecosystems the possibility of being more resilient. Limiting warming to $1.5^{\circ} \mathrm{C}$ and not $2^{\circ} \mathrm{C}$ would minimise the serious consequences on the health and well-being of populations and ecosystems. To achieve this goal, the pace of implementation of adaptation strategies must be accelerated, in order to initiate large-scale transitions in several areas (energy, transport, agriculture, land use planning). The implementation of these adaptation strategies requires a good understanding of the issue of climate change (CC) (Note 1) and its related challenges by the general population. In this perspective, CC appears as simultaneously a reality, an agenda, a problem, a context, a narrative and a discourse (Geoghegan \& Leyson, 2012). From this point of view, analysing and understanding the social dimensions of CC is indispensable today as they are at the heart of the success or failure of public adaptation policies advocated by scientists and politicians. This understanding of the social dimension of CC is itself dependent on several factors, among which we can cite: the worldview, the political orientation and the values that dictate the everyday behaviour of the general population. This article looks at the influence of these parameters on the belief in $\mathrm{CC}$ and the commitment to fight against the phenomenon. The main question is: to what extent does the worldview, the political orientation and the values of the society or social groups that compose it make it possible to identify and characterise the perceptions of and commitment to adaptation in the face of CC? 
Worldviews can be defined as systems of values and beliefs that justify certain decisions and social behaviours (O'Brien, 2009, Brink \& Wamster, 2018). According to O'Brien and Wolf (2010), values can be understood as desirable elements for individuals and societies while beliefs refer to the idea of holding the truth about a given subject or object (here CC). It is in this general context that we question the key determinants contained in the worldviews, the political orientation, the values and the beliefs that are conducive or not to believing in CC and acting against it. From these angles, our article should shed light on and explain the differences in perception and engagement in the fight against CC in two study sites in the Hauts-de-France region - similar in terms of climate, but different from a socio-economic point of view.

\section{World View, Political Orientation and Values in Climate Change Research: A Review of the Literature}

In this work, we question the world view, political affiliation and values in order to analyse the determinants that encourage people to engage or not in the fight against $\mathrm{CC}$. This approach to $\mathrm{CC}$ is a long-standing minority approach in scientific publications on the subject (Hulme 2009, O'Brien \& Wolf 2010). However, it is decisive for understanding the way in which societies perceive the phenomenon, as well as what drives them to act. In recent years, the scientific community, including researchers in the humanities and social sciences, has become more interested in the values-based, world view approach, and many authors (McCright \& Dunlap, 2011, Pidgeon, 2012, Wamsler, 2018) consider these variables as being fundamental in order to better analyse the social dimensions of CC. This approach allows to question and understand the perceptions of climate change and the implementation of control strategies.

\subsection{World View, Values and Beliefs vs. Climate Change}

First, according to Douglas and Wildavsky (1983), founders of the culturalist approach to risk perception and risk management, societies and/or social groups that share the same values and beliefs tend to experience their relation to the environment and the associated risks in the same way. They show that in decision-making, beliefs and values are key factors in the direction of action of individuals and social groups. In this sense, these two authors evoke four major visions of the world: individualist, equalitarian, fatalist and hierarchist (see also Thompson, Ellis, \& Wildavsky, 1990). Each of these worldviews refers to a certain perception of risk (here in terms of the climate) and nature in general. These perceptions are governed by a social and political order that directs and influences behaviour in regards to climate risk. More recently, another major contribution by Brink and Wamster (2018) is a continuation of Douglas and Wildavsky's (1983) cultural approach to risk. In this work, Brink and Wamster (2018) focus on adaptation in the face of CC and show that those with a community-based vision are more inclined to take adaptation measures. Individualists, who we could find, for example, among entrepreneurs, evaluate their own ability to adapt as higher and are reluctant to take collective measures of adaptation. In the case of fatalists, who are also often the marginalised of society, they have a lower motivation in the fight against CC. This is explained by a certain form of resignation and helplessness experienced by them. In addition, these authors observe a positive correlation between being fatalistic and being older. We will see in this study if this framework of interpretation can or cannot be applied to our study sites. Moreover, in this study, no specific adaptation strategy was observed among hierarchists.

In terms of the influence of values, according to Brink and Wamster (2018), there are three main aspects that can influence perceptions and action in the fight against CC. These three aspects are economic, ecological and social. Economic values make it possible to question the issue of profit, selfish interest vis-à-vis $\mathrm{CC}$ and its consequences. Concerning ecological values, they involve environmental sensitivity in the philosophy of the new ecological paradigm (NEP) of Dunlap, Van Liere, Mertig, and Jones (2000). (Note 2)

In this sense, the relationship of man to nature, in terms of profit but also of well-being and sustainability of natural resources, is analysed in an eco-centric perspective. From the point of view of the social aspect, it is a question of altruism. In other words, the concern for personal well-being and that of others (including nature) can be an important vehicle for commitment to protecting the climate. Several authors have emphasised the relationships and interactions between values and beliefs on the one hand and scientific knowledge on the other. Indeed, in their respective studies, Adger, Barnett, Brown, Marshall, and O'Brien (2013) and Persson, Sahlin, and Wallin (2015) have shown the existence of a dynamic interaction between values and beliefs and the issue of CC. According to these authors, the current development of scientific knowledge regarding CC offers a framework of reflection likely to question certain beliefs. Thus the influence of scientific knowledge on popular beliefs about $\mathrm{CC}$ is variable: when scientific and secular knowledge is in agreement, confirmation bias comes into play, when it is not, secular knowledge strongly resists and scientific knowledge has a weak influence.

On the one hand, scientific knowledge can serve to reinforce the beliefs that structure and govern the interactions between societies and their environment. In this sense, confirmation bias may lead individuals to select elements 
from scientific discourse that appear to them to confirm preconceived ideas inherited from societal beliefs (Nickerson, 1998). On the other hand, based on pre-existing beliefs and values in relation to current scientific knowledge, scientific discourses and recommendations regarding adaptation can be completely challenged due to being contrary to the previously conveyed values and beliefs. In this context, religious belief is also an element that may favour or hinder commitment towards fighting CC. Using the example of American evangelists, Wilkinson (2010) shows that religious belief and environmental engagement are not necessarily opposed. According to him, theological and moral teachings bring an extra dimension to the work on CC largely dominated by scientific and political speech. In contrast, Ecklund, Scheitle, Peifer, and Bolger (2017) found climate skepticism to be higher among evangelicals than non-religious individuals.

In the light of these different sets of values and beliefs, we will seek here to analyse the different attitudes towards $\mathrm{CC}$ in France.

\subsection{Political Orientation vs Climate Change}

The last pillar of the $\mathrm{CC}$ approach via world views and values is political. In this respect, the literature very clearly shows the influence of political ideology on CC denial (McCright \& Dunlap, 2011). In general, Hakkinen and Akrami (2014) have highlighted the existence of a strong correlation between right-wing authoritarian ideology and $\mathrm{CC}$ denial. In this sense, they show that political orientation and environmental values are relevant variables for studying attitudes and commitment to CC, results confirmed more recently by Ziegler (2017). Moreover, in the United States of America, McCright and Dunlap (2011) as well as Pidgeon (2012) have shown that right-wing conservatives and Republicans have very weak convictions about CC compared to the American left (Democrats) and the Liberals.

In Europe, political orientation and its implications for the perception of $\mathrm{CC}$ remains very little studied. Few scientific studies analyse the place of CC in the discourses of different European political movements. However, Möhler, Piet, and Zaccai (2015) have analysed the political polarisation around the climate issue in the European Union and show that climate-skepticism is almost exclusively an aspect of right-wing parties, that it is totally absent from the left or centre parties. On the right of the European political spectrum, especially among the extremes, the issue of $\mathrm{CC}$ is relegated to the background in favour of security and identity issues. However, this far-right skepticism towards CC, a minority view in Europe, is less in denial about the reality of the phenomenon and its anthropic origins than what can be found in the USA, where denial is very clearly expressed by some Republican voters and leaders (Möhler, Piet, and Zaccai, 2015). In Europe, the issue of CC is increasingly emerging in the outlook of political parties that call themselves social democrats (or socialists). In this political movement, situated for the most part between socialism and liberalism, the welfare state, equality policies and the need to regulate economic life constitute the main ideological foundations. According to Special Eurobarometer 313 (2009), politicians and supporters of the European left are undertaking more measures to combat CC. They are more convinced of the reality of the phenomenon and the urgent need to act. Moreover, in the left-wing programmes, more people in Europe $(67 \%)$ highlight the benefits of a greener economy that participates in the fight against climate change. Thus, we can say that in Europe there is a noticeable difference between citizens situated on the left of the political spectrum and those on the right in regards to the subject of CC.

In France, a recent survey of the FIFG for the Fondation Jean-Jaurès and Conspiracy Watch (2017), shows that $77 \%$ of left supporters think that CC is certainly a problem caused mainly by human activity, compared to $53 \%$ on the right and $53 \%$ of Front National supporters. As for skeptics, 35\% of right-wing voters say that it is not yet clear whether global warming results from human activity or solar radiation. They are less numerous on the left, $18 \%$, and a little more so on the extreme right, $27 \%$ of the Front National. (Note 3). Moreover, we observe that in the Front National, $9 \%$ of voters think that we are not yet sure that the climate is getting warmer and $11 \%$ say that global warming does not exist, that it is primarily a hypothesis championed by politicians and scientists in order to advance their own interests. Regarding this last point, $1 \%$ of voters on the left have the same conviction, compared to $5 \%$ on the right.

In light of these elements, we will try to analyse if this right-left polarisation is confirmed in our study sites. We hypothesise that if $\mathrm{CC}$ representations are politically divisive, the degree and forms of engagement in the struggle against the phenomenon must also follow political orientations. In other words, we postulate that the fact of actively engaging or not in the fight against CC partly depends on political sensitivity. This political sensitivity is itself influenced by socio-occupational status, world view and the main values held (Bréchon, 2014, Bréchon \& Gonthier, 2017). This approach will be all the more central in this work that the literature review shows us that in Europe, and particularly in France, there is little research on the barriers and the driving forces 
that condition the commitment of the populations in the fight against CC according to their beliefs, values and or vision of the world unlike Anglo-Saxon countries (Blennow, Persson, Tomé, \& Hanewinkel, 2012; Glaas, Neset, Kjellström, \& Almås, 2015; Hegger, Mees, Driessen, \& Runhaar, 2017; Brink \& Wamster, 2018).

\section{Method}

\subsection{Study Sites}

Two study sites were selected in the Hauts de France region on the basis of both geographical characteristics and socio-economic criteria: Lille and Chauny (Fig. 1). The choice of these two sites makes it possible to compare perceptions and actions undertaken in a small rather rural town on the one side and those that characterise a large urban municipality on the other. Located in the 4th largest urban area of France, outside Paris, the central municipality of Lille had 233000 inhabitants in 2015. As for the municipality of Chauny, located in the central-west of the department of Aisne, its population was estimated at 11800 inhabitants in 2015. The second reason justifying the choice of these two sites is related to the comparable climatic context that characterises them. In fact, the municipalities of Lille and Chauny are subject to a temperate climate with oceanic influence. Between 1955 and 2016, the climatic records show a similar trend to warming in these two sites, with respectively an average increase of about $1.75^{\circ} \mathrm{C}$ in Lille and $1.77^{\circ} \mathrm{C}$ in Saint-Quentin (reference station for Chauny, 30 kilometres away).

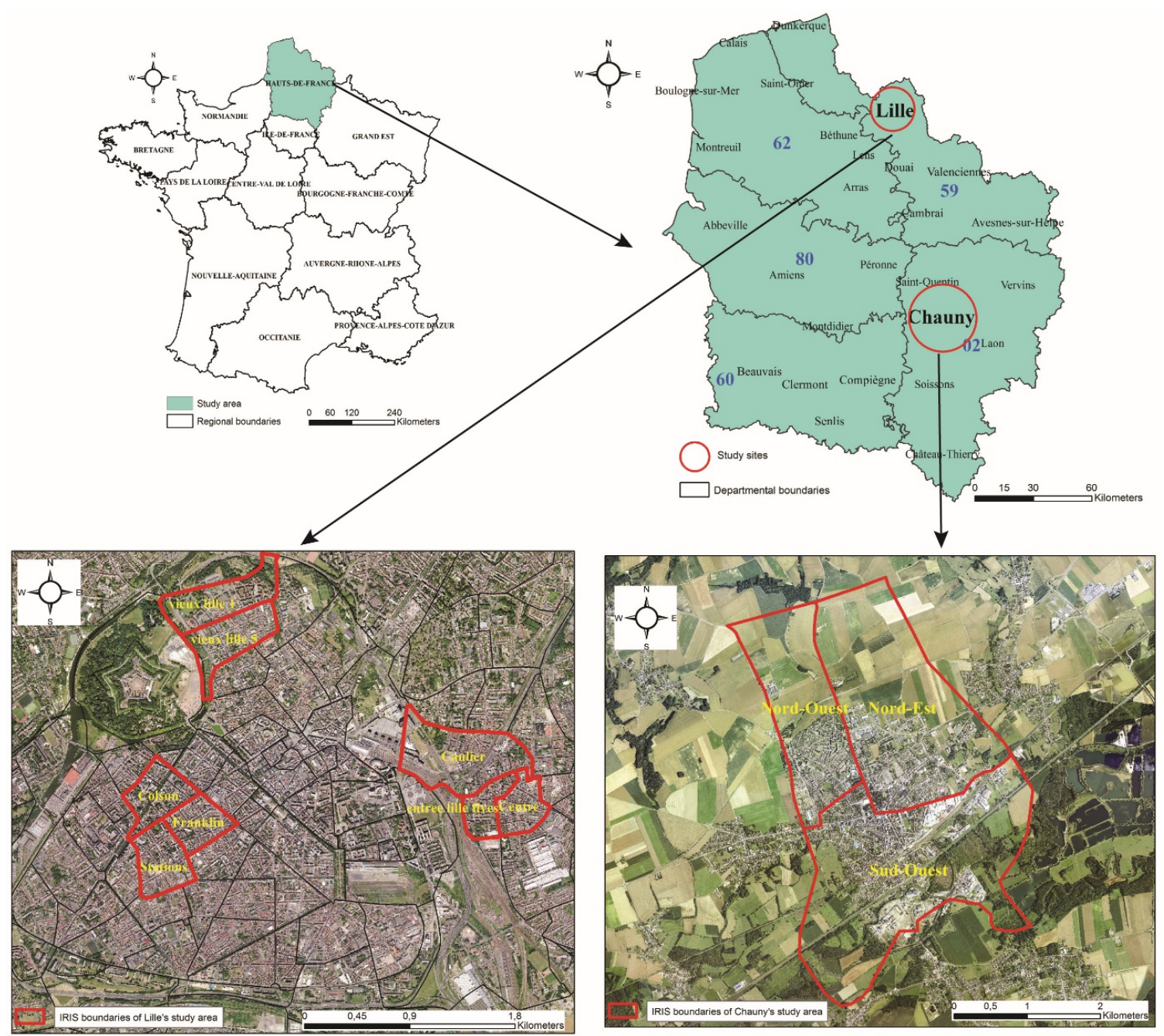

Source: IGN and INSEE geographic data, IRIS boundaries 2.1 (2016), GADM data (2018). Map by: O. Marega, 2019

Figure 1. Location of the Lille and Chauny survey sites

\subsection{Data Collected}

Data was collected between May and September 2017 during the questionnaire survey. The survey was 
conducted face-to-face at the respondent's homes for the vast majority of them, and in the workplace for some tradesmen and craftsmen. The samples from the two sites were constituted using the quota method, based on three socio-demographic criteria: gender, age and socio-professional category. The final sample includes 433 individuals, of whom 53\% live in Lille and $47 \%$ in Chauny. Within it, the distribution of respondents is fairly balanced: $51 \%$ women and $49 \%$ men. Young people between the ages of 15 and 29 are in the majority, as $35 \%$ of the surveyed population. In regards to the age pyramid, our sample relatively clearly reflects the reality of the two reference populations. Indeed, $48 \%$ of respondents in Lille are aged between 15 and 29 , with $53 \%$ among the population of Lille (Tab.1). In Chauny, there is a rather ageing population, with $32 \%$ aged over 60 in the reference population and nearly $30 \%$ in the sample.

In terms of socio-professional categories, there is an imbalance related to the structure of the two reference populations (Lille and Chauny). In the Lille sample, we note $19 \%$ managers and higher intellectual professions, the same as in the reference population, compared to only $6 \%$ in the Chauny sample ( $4 \%$ in the reference population). In Chauny, the working population is under-represented in the sample: $6 \%$ compared to $16 \%$ in the reference population. For the Lille site, it is the associate professionals that are underrepresented in our sample, with $6 \%$ compared to $15 \%$ in the reference population. Despite these imbalances in the socio-professional categories, we did not carry out an adjustment in the classic sense of the term but decided to reassign the retirees to their former categories, in particular to increase the number of workers and associate professionals, and to allow their comparison. (Note 4). This recoding, justified by the fact that retirees perceptions is less related to their current retiree status than to their last occupation (Chauvel, 2010), allows the presence of associate professionals to be increased from $6 \%$ to $10 \%$ in the Lille sample and that of workers from $6 \%$ to $12 \%$ in Chauny (see Table 1).

Table 1. Summary of the sample structure surveyed compared to the reference population of both sites

\begin{tabular}{|c|c|c|c|c|c|c|}
\hline & \multicolumn{3}{|c|}{ LILLE } & \multicolumn{3}{|c|}{ CHAUNY } \\
\hline & $\begin{array}{l}\text { Reference } \\
\text { population }\end{array}$ & $\begin{array}{l}\text { Surveyed } \\
\text { sample }\end{array}$ & $\begin{array}{l}\text { Corrected } \\
\text { sample* }\end{array}$ & $\begin{array}{l}\text { Reference } \\
\text { population }\end{array}$ & $\begin{array}{l}\text { Surveyed } \\
\text { sample }\end{array}$ & $\begin{array}{l}\text { Corrected } \\
\text { sample* }\end{array}$ \\
\hline \multicolumn{7}{|l|}{ Gender } \\
\hline Women & $50 \%$ & $47 \%$ & & $55 \%$ & $56 \%$ & \\
\hline Men & $50 \%$ & $50 \%$ & & $45 \%$ & $44 \%$ & \\
\hline \multicolumn{7}{|l|}{ Age groups } \\
\hline $15-29$ & $53 \%$ & $48 \%$ & & $24 \%$ & $21 \%$ & \\
\hline $30-44$ & $24 \%$ & $25 \%$ & & $21 \%$ & $24 \%$ & \\
\hline $45-59$ & $12 \%$ & $11 \%$ & & $24 \%$ & $26 \%$ & \\
\hline $60-74$ & $7 \%$ & $11 \%$ & & $19 \%$ & $20 \%$ & \\
\hline $75+$ & $4 \%$ & $5 \%$ & & $13 \%$ & $9 \%$ & \\
\hline \multicolumn{7}{|l|}{$\begin{array}{l}\text { Socio-occupational groups } \\
\text { and categories }\end{array}$} \\
\hline Farmers & $0 \%$ & $0 \%$ & $0 \%$ & $0 \%$ & $0 \%$ & $0 \%$ \\
\hline $\begin{array}{l}\text { Tradesmen, shopkeepers and } \\
\text { heads of businesses }\end{array}$ & $2 \%$ & $7 \%$ & $8 \%$ & $3 \%$ & $3 \%$ & $5 \%$ \\
\hline $\begin{array}{l}\text { Managers and higher } \\
\text { intellectual professions }\end{array}$ & $19 \%$ & $19 \%$ & $24 \%$ & $4 \%$ & $6 \%$ & $11 \%$ \\
\hline Associate professionals * & $15 \%$ & $6 \%$ & $10 \%$ & $11 \%$ & $11 \%$ & $18 \%$ \\
\hline $\begin{array}{l}\text { Services, sales and } \\
\text { administrative employees }\end{array}$ & $13 \%$ & $7 \%$ & $11 \%$ & $18 \%$ & $19 \%$ & $28 \%$ \\
\hline Workers * & $6 \%$ & $2 \%$ & $3 \%$ & $16 \%$ & $6 \%$ & $12 \%$ \\
\hline Retired* & $10 \%$ & $14 \%$ & $0 \%$ & $29 \%$ & $30 \%$ & $0 \%$ \\
\hline Others not in work & $34 \%$ & $44 \%$ & $45 \%$ & $19 \%$ & $24 \%$ & $24 \%$ \\
\hline
\end{tabular}

* The corrected sample represents the structure of the surveyed population by reassigning retirees to their former occupations and socio-professional categories. 


\subsection{Analysis Variables}

Firstly, the variables studied fall into four categories: 1) worldview and political orientation, 2) values, 3) perception and knowledge of CC, 4) fight against CC. The worldview has been understood from the way in which respondents define themselves from the point of view of their religious and/or spiritual beliefs. On the one hand there are those who define themselves as "believers" and on the other those who call themselves "atheists or agnostics". We also included in this first category, the vision of the ecological world that the people surveyed may have. We then used the answers to the question: do you think that the following natural resources are limited, unlimited? the resources cited were water, air, agricultural land, vegetation and biodiversity. We postulate that, in general, the relation to the environment and the issue of CC is different if we consider that natural resources are finite in time or on the contrary infinite. This issuen therefore questions the perceptions of the sustainability of resources and we believe that it also refers to different attitudes towards belief and engagement in the fight against CC.

Regarding the political orientation of the respondents, this was studied based on the following two questions: on an axis graduated from 1 to 10 , can you position yourself politically (1 being the leftmost, 10 the rightmost)? Do you vote for environmental political parties (green parties)? (Note 5).

As far as values are concerned, they have been analysed through the following questions: In general, do you trust what scientists say about CC? Do you have confidence in the steps public authorities have taken to combat CC? Are you a member of an association or NGO? The two questions about trust in scientists and politicians refer to values about the credibility of their action and can therefore influence commitment to the climate. We also took into account the associative engagement in order to characterise values. Indeed, the associative engagement contains an underlying dimension to the action which refers to a sensitivity towards certain causes, certain subjects and principles. It can be considered as an indicator of the relationship to others (altruism), including nature.

The last two variables directly concern $\mathrm{CC}$ in regards to perception and taking action against it. Regarding the perceptions and knowledge of $\mathrm{CC}$, we have studied it through the following questions: if I tell you that the global climate is changing, would you agree with me? Would you say CC is an urgent issue? On a scale of 0 to 10 , can you locate your level of knowledge about CC?

Regarding the engagement to combat the phenomenon, this has been analysed through the following questions: do you think, broadly speaking, that it is possible to combat CC? do you think (at your personal level) that you can combat CC? Have you taken personal measures to combat CC?

The additional variables taken into account in this study concern the socio-professional and geographical characteristics: place of residence, gender, age, level of education, PCS, economic standard of living). (Note 6).

\subsection{Process for the Analysis}

We first used descriptive statistics to analyse the distribution of responses for each of the variables studied. The frequencies of each modality made it possible to obtain an overview. From there, we carried out tests of bivariate correlations, which proved to be significant. These include the tests between political orientation, religious belief and associative engagement which all proved to be significant compared to the belief in CC, the urgency of combat and the move towards taking action through making steps to fight against $\mathrm{CC}$.

This step is a prerequisite that has guided the combined analysis of all of the variables previously cited to explain climate belief and engagement within the two sites according to the worldview, political orientation and/or values of their inhabitants. The second phase consisted of in-depth analyses in the form of factor analysis, which is justified by its effectiveness in highlighting the links between more than two variables (Michel-Guillou, 2014). Thus, we have opted for multiple factor analysis "MFA" (Escofier \& Pagès, 2008) because it allows to work from groups of variables by rebalancing the significance of each of them, their number and their variability being different. It also allows a very fine identification of the links between these groups using specific indicators. The aim was to first identify the proximities between worldview, political orientation and values on the subject of CC perception and climate engagement.

In a second step, we sought to highlight the groups of people or scale factors relating to the climate perception and engagement according to the links identified between worldview, political orientation and values. Finally, we wanted to determine if the place of residence or the sociodemographic variables intervened in the characterisation of the identified groups.

In this approach, several variables were tested beforehand through a simple multiple correspondence analysis (MCA) associating all the variables suggested for the analysis. This test removed the variable that places CC 
among a set of environmental problems, due to the lack of links with the four groups.

We then carried out the first phase of the MFA using MCAs separated by group, which allowed the highlighting of the different factors or dimensionality of their own. These preliminary MCAs revealed the potential links between the different dimensions. The next step involves the global analysis of groups by MFA. Four groups were used to define the factorial space (active variables): worldview and political orientation ( 8 variables), values ( 3 variables), perception and knowledge of climate change ( 4 variables), the fight against climate change (3 variables). A fifth group (6 variables), taking into account the social and geographical characteristics of the respondents, was added. For the missing values of some variables, we applied the "nearest neighbour" method. (Note 7) This had little influence on the final result, as there are very few missing values $(<0.4 \%)$. All the statistical work was carried out with XLSTAT-Psy software - version 18.03 and the multiblock and 3DPlot data analysis tool in addition to the graphic representations.

\section{Results}

\subsection{Descriptive Analysis of Factorial Axes}

The MFA applied to these data shows (Fig.2) that the relations between the dimensions characterising on the one hand each group taken individually and all the active groups are rather moderate. However, if one observes the first main component of the MFA (axis F1), proximities exist between the first factorial dimensions of each of these active groups. This axis, common to the four groups, stands out clearly from the following; its eigenvalue is 2.06 (or $5.63 \%$ variability), that of the others does not exceed 1.43 . The interest of this axis is that the contribution of each of the groups is rather balanced (between 19 and 32.5\%) and that the correlations of the first partial axis of the separated MCAs (predominant dimensions of each group) with F1 are of the same order of magnitude. Despite these average values, we can consider that, given the number of people interviewed $(\mathrm{N}=433)$ and the number of associated groups, this factor provides a very interesting insight into the links between worldview, political orientation, and values on the subject of belief and climate engagement.

The F2 axis, with 1.425 eigenvalue (3.9\% variability), relies heavily on 3 groups: values $(30.6 \%$ of contributions), CC perception and knowledge (32.9\%) and combat (22.4\%). In detail, this component moderately associates three partial components of the MCAs. The first two partial axes are focused on the fight against CC and the characteristic values of those who do or do not take actions against it. The third partial axis concerns the perception and knowledge of CC. The statistical correlations of these 3 axes are quite similar. They confirm the existence of a genuine link between them.

The eigenvalue of the next axis, F3 (3.5\% variability), is very close to the previous one. However, this one relies heavily on the two groups: values ( $41.3 \%$ of contributions) and perception and knowledge (38\%), and only the first partial axis of the values group is expressed sufficiently, the others being weak or very weak. This confirms that $\mathrm{F} 3$ is less relevant to study than the first two.

After checking the individual contributions to see if the MFA components are based on enough observations, we concluded that the first two components of the MFA, the F1 and F2 axes, deserve a more detailed analysis because their content proves to be rich in information (Fig. 2). 


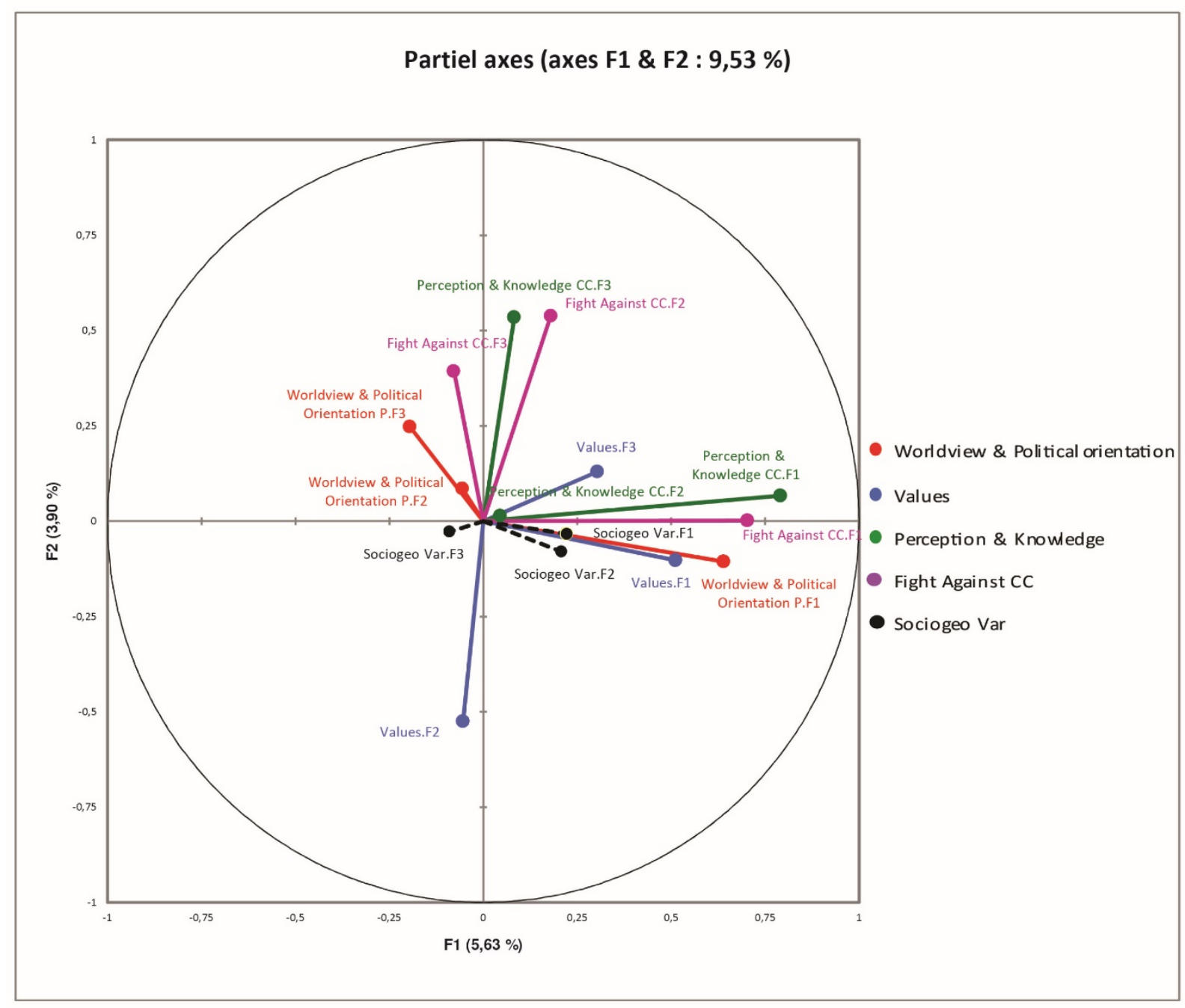

Figure 2. MCA preliminaries

Note: Sociogeo Var $=$ Sociogeographic Variables

Moreover, we observe that the structure and the dimensions of the group of additional variables representing the sociogeographic characteristics do not associate well with the other active groups, and in particular here on the MFA targeted factor. (Note 8)

However, taken as illustrative variables, the social and geographical characteristics are sufficiently correlated with this axis to be used in the analysis aimed at a finer characterisation of the active groups. All the modalities of the active variables have been reported on the F1-F2 plane of the MFA, in the form of centroids (centres of the point cloud of the modality). We have selected the centroid for its ability to highlight a greater or lesser link depending on the distance to the origin 0 of the factorial axis considered.

In addition, we checked the presentation quality of each of the modalities by active variable to identify and select those that best fit this factor (Busca \& Toutain, 2009). Figure 3 shows the modalities most related to F1 and F2. (Note 9)

First of all, compared to the first partial axes highlighted by the preliminary MCA, it should be noted that it is the perception \& knowledge of CC (32.5\%) then, in a balanced way, the fight against CC (25.9\%), the worldview and the political orientation (22.7\%) that best relate to the F1 axis of the MFA. The contribution of the last group, the values, represents $18.8 \%$. This F1 axis represents the degree of certainty about the reality of CC and its causes, and the level of engagement in the fight against CC. Given the ordered alignment of most of the modalities relating to several ordinal variables of distinct groups and given the good quality of individual 
representation on the $\mathrm{F} 1$ component, our analysis will be focused on this axis 1 .

We have previously seen that the F2 axis of preliminary MCAs is structured around the following variables: perception \& knowledge CC (32.8\%), values (30.5\%) and fight against CC (29.3\%). Starting from this, the second component of the MFA makes it possible to highlight on the factorial level, on the one hand the sceptical (and not militant) inhabitants, who do not express opinions on the fight against CC or confidence in the measures and actors (value), and secondly those with a rather unfavourable opinion towards scientists and measures advocated by public authorities (values).

In sum, the descriptive analysis of the MFA tells us that there is a clear opposition between those who believe in CC (the convinced) and those who do not believe in it or who do not give a response (sceptics). What roles do the worldview, political orientation and values play in this opposition?

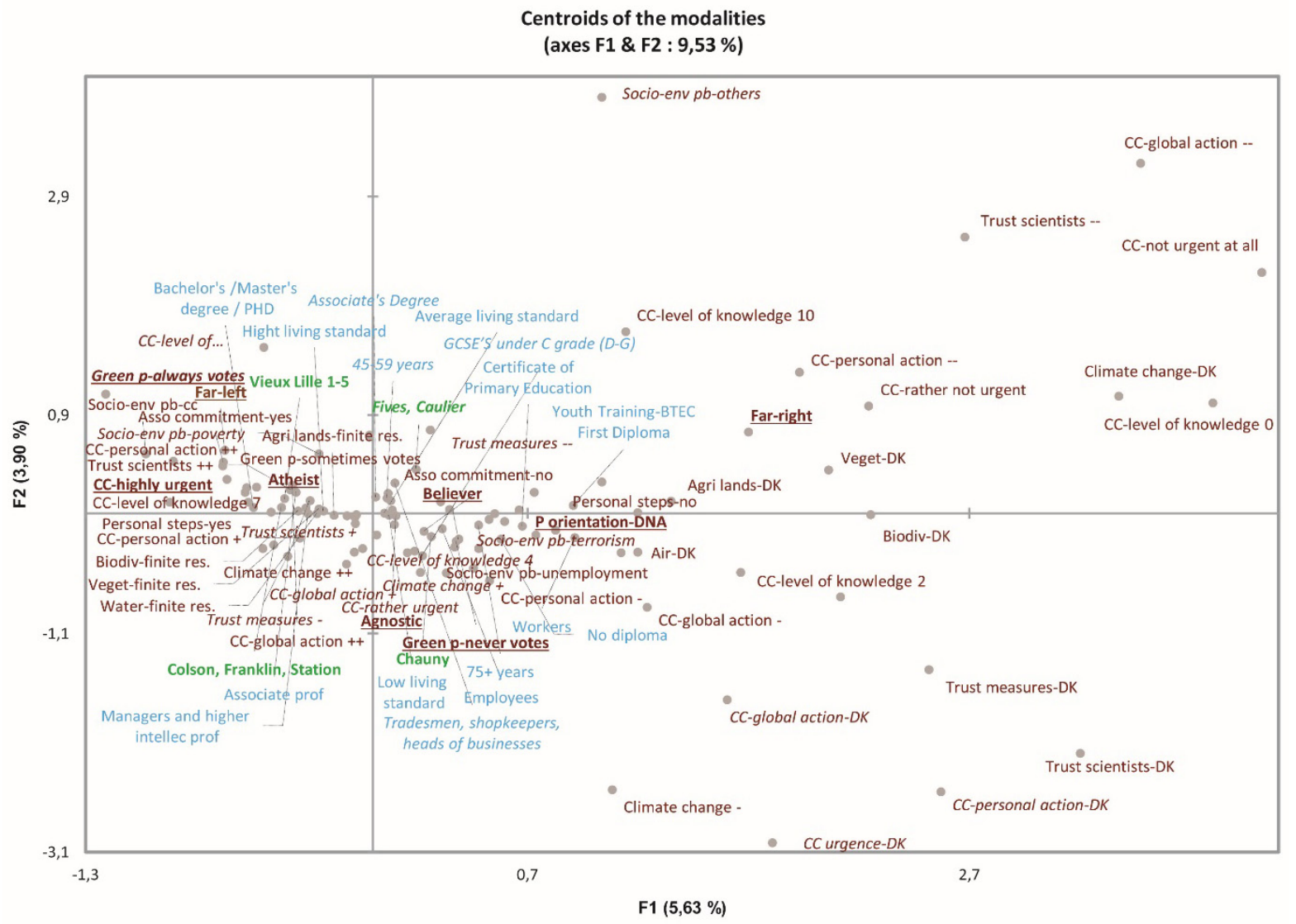

Figure 3. Centroid of the modalities best represented on the plane F1 and F2

Note: DK=Don't Know, DNA=Did Not Answer, Green $p=$ Green parties , Asso=Association, Finite res=Finite resource, Socio-env $p b=$ Socio-environmental problems, P-orientation $=$ Political orientation, CC=Climate Change

\subsection{Belief in CC and Commitment to Fight}

In our survey, those convinced about the reality of $\mathrm{CC}$ are mostly atheists, with an ecological vision very focused on the finiteness of natural resources. Across the entire sample surveyed, those who think that resources such as air $(47 \%)$, water $(72 \%)$, agricultural land $(84 \%)$ or biodiversity $(80 \%)$ are limited are among the most convinced of the reality of CC. This view of the finiteness of natural resources questions, in other words, the question of their sustainability. From this point of view, the respondents in this group are in total agreement that the global climate is changing and think that $\mathrm{CC}$ is a very urgent matter that needs to be dealt with. Another element that characterises these people is the political orientation. In total, in our sample we have $19 \%$ of voters on the far left and $18 \%$ of voters on the left. Of these, $80 \%$ of far-left voters and $78 \%$ of left-wing voters strongly agree that the global climate is changing and there is an urgent need to act against CC. In line with the work of McCright, 
Marquart-Pyatt, Shwom, Brechin, \& Allen, (2016), this result confirms the fact that we are more concerned with the climate when we are located on the left rather than the right side of the political spectrum. In addition, in the entire sample, $36 \%$ sometimes, often or always vote for political parties labelled as environmentalists and among those who display this environmental awareness, nearly $85 \%$ of them completely agree that the global climate is changing and urgent action is needed.

Thus it can be said that pro-environmentalism characterises this group well and this seems to be a key factor in favour of climate action. Indeed, in terms of climate engagement, we observe that activism in favour of the fight against CC is very significant in this group (Fig. 4). Many people are convinced that we can fight CC not only collectively but also individually. We observed a significant correlation between environmental values and commitment to the fight against CC. People who tend to vote for environmental parties (36\% in total) are more likely (75\%) to take personal action against CC. As far as right-left political polarisation is concerned, among the $19 \%$ of far-left voters (in the surveyed population as a whole), it can be noted that $68 \%$ of them engage in the fight against $\mathrm{CC}$ by taking personal measures. On the other side, among far-right voters (3\% declared and $25 \%$ not assumed), we note that nearly $67 \%$ do not engage in the fight against CC. (Note 10)

In right-wing voters, $50 \%$ say they take action against $50 \%$ who do not. While on the left, $65 \%$ take action against $35 \%$ who do not opt for personal measures of combat.

If we now take into account religious beliefs and values of individuals, crosses show that $71 \%$ of those who declare themselves atheists have taken measures against CC. While among believers, attitudes are differentiated into two groups of equal proportions: half $(50 \%)$ implement measures while the other half $(50 \%)$ do not implement them. Moreover, among the respondents, this engagement in the fight against $\mathrm{CC}$ is reinforced by the sensitivity to values, particularly related to trust and associative engagement. There is a propensity to take personal action against $\mathrm{CC}$ because people are more confident in the views expressed by the scientific community and have less trust in the measures taken by the authorities. Confidence in science appears to be a catalyst for taking action against $\mathrm{CC}$. This confidence in science, particularly on the issue of $\mathrm{CC}$, can be explained by the convergence of scientists towards an increasingly strong or even very strong consensus about the reality of $\mathrm{CC}$, the physical dynamics at stake and the potential consequences of the phenomenon.

Regarding the value of activist engagement (for others or for nature), this also seems to be an important driver in decision-making to combat CC. Among those who are involved in an association or NGO, $75 \%$ say they take personal action against climate change against $24 \%$ who do not commit themselves.

Finally, from a socio-geographical point of view, we observe that this population of those who are convinced about and committed to fight CC is better represented in Lille (Vieux-Lille, Colson Franklin, Station) and less in Chauny. Executives and those with higher education and a high standard of living are also better represented, partially overlapping the previous one.

\subsection{Lack of Belief in CC and Inaction}

Axes 1 and 2 of the MFA show that respondents not fully convinced of the reality of CC are divided between those who doubt the reality of CC, who we will call climate-sceptics, and those who are in complete denial, who we will call climate-deniers. The distinction is necessary, since there is a dimension of doubt inherent in climate-scepticism that is not found in the climate-deniers: they do not doubt, they "know" and are convinced that $\mathrm{CC}$ does not exist.

The analysis of MFA factorial planes shows that individuals who are more or less in agreement that the global climate is changing are getting closer to those unconvinced of CC's reality in terms of engagement. This inclination in the factorial plane justifies analysing in a single block those who rather agree with the fact that the world climate is changing $(24 \%)$, those who rather disagree $(1 \%$,) and those who completely disagree $(1 \%)$.

Link analysis shows that this block is shared between agnostics and believers. In terms of the environmental vision of the world, it is difficult to characterise this group because most of the individuals say they do not know if the natural resources such as biodiversity, agricultural land or air are limited or not. In terms of political sensitivity, this block is mainly made up of individuals voting right and far right (declared + non-assumed) in relation to the entire surveyed population. With regard to taking action against CC, this population is globally characterised by its abstention from action (Fig. 4). There are two sub-groups on this question: the first is made up of those who consider that nothing can be done to combat $\mathrm{CC}$, both individually and collectively, the second sub-group is rather undecided because the individuals do not know if we can fight or not against the phenomenon.

How can we go further in explaining this non-engagement? 
Two factors seem to provide elements of analysis: the values put forward by the inhabitants and the sociogeographical characteristics. Indeed, trust in the measures taken by the public authorities and confidence in the scientific community suffer from the same weakness in both cases. The people surveyed in this group therefore do not trust science or politics. These results echo the findings of (Peretti-Watel \& Hammer, 2007, Giddens, 1994) who note that the lack of trust in political authorities induces a weak capacity of administrations and elected officials to involve the public in the climate issue. Thus, this lack of confidence sometimes gives rise to low awareness of climate issues and even sometimes to a certain mistrust of state and scientific institutions. This is a source of reluctance to fight against CC, contrary to what was observed among the convinced. This reluctance arises from the fact that a part of the population feels that the conduct and the concrete realisation of the measures recommended by the public authorities and scientists is lacking, as illustrated by these reports below (Note 11):

"Politicians talk about it but do nothing; we can't do anything, they don't listen to us even at the local level", observation no. 80, worker, 8th July, 2017 in Chauny.

"When will politicians stop taking us for idiots; we should put an end to lobbying", observation no. 195, college teacher, 30th June, 2017 in Chauny.

One can speak of a certain form of rejection of the political and scientific system, all the more so as the political orientation of this group leans clearly towards the extreme right. This non-engagement with climate issues also seems to go hand in hand with non-associative engagement (for others or for nature), which relatively characterises the members of this group.

In terms of sociogeographic characteristics, we can observe that this non-belief in $\mathrm{CC}$ and this non-engagement in terms of combating it more specifically concerns individuals of the skilled trades, merchant, worker and employee categories, with a low to medium standard of living, as well as a low level of education. Consequently, if we observe an interesting proximity between the populations of Chauny and the Lille district of Fives-Caulier regarding this non-engagement with climate issues and this non-belief in the reality of the CC and the urgency of acting, this is partially explained by the similarities of the two populations in terms of their overall low standard of living. Moreover, our results show that they focus more on prioritising socio-economic problems such as unemployment and terrorism than on the issue of CC. 


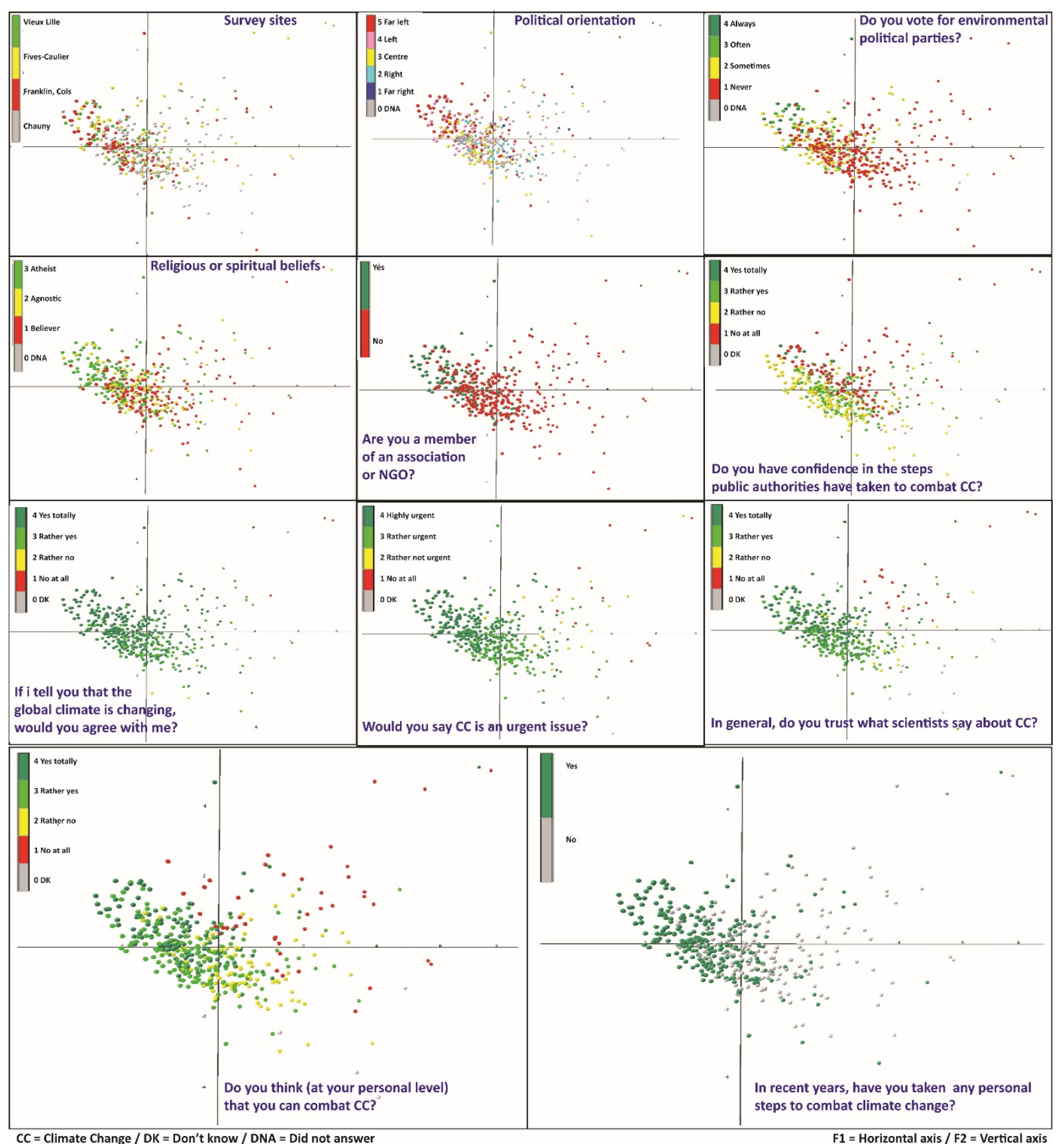

Figure 4. Projection in the space of the partial clouds resulting from the MFA

\section{Discussion and Conclusions}

At the end of our analysis on the role of the worldview, political orientation and values of individuals regarding their belief and engagement in the fight against $\mathrm{CC}$, we can keep the following points in mind: 1) an environmental world view centred on the finitude of natural resources gives rise to a strong belief in the reality and urgency of $\mathrm{CC}$ and a commitment to fight against it 2) the more an individual is politically and ideologically situated to the left of the political spectrum, the greater the awareness of CC and the greater the commitment to fight against the phenomenon, 3) conversely, the more an individual is situated to the right of the political spectrum, the lower the awareness of $\mathrm{CC}$ is, with a decreased tendency to take measures to combat it, 4) associative engagement and trust in scientific and political institutions seem to be values that are favourable to taking action on climate issues.

In the light of this work, several questions emerge: what does the political polarisation regarding the climate 
issue evoke? A simple effect related to partisan affiliation or a real ideological divide? On the other hand, does the propensity of the wealthier and higher-educated to take action mean that $\mathrm{CC}$ is a specific issue and concern for this group?

In our view, far from being simply the reflection of a partisan affiliation, we think like McCright et al., (2016) that the political polarisation regarding $\mathrm{CC}$ refers both to the ideological foundations of these two political movements but also to sometimes conflicting interests between the actors. For a large part of the population who identify with either the left or the right, there is the implicit issue of the principles, beliefs and values that are essential for building an ideal society. In our increasingly modern and liberal societies, the world view of those who rank on the right, more individualistic, encourages relying first and foremost on oneself in order to cope with growing competition and insecurity, while in the world view of those who rank on the left, the emphasis is placed on the role of the welfare state, in charge of protecting the weakest and fighting against inequalities. Applied to an environmental and societal problem such as CC, this right/left cleavage means taking into account interactions between humans and their environment in the etymological sense of ecology. Therefore, from the point of view of left-wing ecologist thought, capitalism, mixed with a certain idea of infinite economic growth, must not be left to spontaneously operate either, the public authorities have the duty to act in order to preserve the harmony and fragile balances between humans and their environment. This means, for example, taking into account the potential impacts on the environment of the various land development and economic development projects. This attitude is not appropriate for those who adhere to liberal thinking, who tend to refer to the market as well as the economic equilibrium and environmental balance. In this respect, we can refer to the "entrepreneur" or "individualist" pole of Douglas and Wildavsky's (1983) culturalist model, where we find people who are particularly concerned about immediate benefits and who are not interested in long-term risks, whether they are environmental or not. Finally, the current development of the French political framework certainly deserves other more targeted studies on the environmental tendencies of those displaying a "neither left nor right" position. There is a growing emergence of rejection of the capitalist consumer society, but which does not benefit great ideals and socialist or communist projects, judged as utopian.

Regarding the implications of religion on the perception of $\mathrm{CC}$ and attitudes adopted, we observed a significant contrast between those who declare themselves to be atheists and those who claim to be believers. In the former, the conviction about the reality of $\mathrm{CC}$ and the urgency of acting is stronger than the second, where the situation is in balance between the convinced and unconvinced. Given this finding, it remains difficult to draw a definite conclusion about the implications of religious beliefs regarding CC. Among those who declare themselves to be believers, there are two positions leading to opposing attitudes towards taking action against CC. On the one hand, there are those who see $\mathrm{CC}$ as being the manifestation of the divine will against which man can do nothing. This attitude is in line with the fatalists of culturalist analysis. On the other hand, there are the proponents of an eco-religious philosophy based on the idea of taking care of the divine creation: Genesis 2:15 "The Lord God took the man, and placed him in the Garden of Eden to cultivate it and to keep it." This kind of reasoning emphasises man's responsibility towards nature and therefore towards CC. In this second trend, religious moral convictions also incite action since the consequences of the phenomenon would first of all hit the poor hardest, those who need the help of every member of society according to their means, actions and deeds. From this perspective, religious belief can be considered as an important variable in the commitment to the climate cause.

In addition, we observed that the move to take action against $\mathrm{CC}$ is also dependent on the socio-economic status of the respondents. People with high incomes and a high level of education appear to be more favourable to the issue of $\mathrm{CC}$ in terms of perception and even more so in terms of taking action. They are more inclined to take action against CC. This can already be seen in Beck (1992), for whom climate change remains the concern of a better educated, richer elite, capable of appropriating the messages conveyed by scientists and climate experts. These results are also in line with Bozonnet (2011), who observed that the intensity of awareness of CC and the urgency of acting is well correlated with social inequalities. However, even if this correlation is statistically established, it does not necessarily mean that people with higher education and a higher standard of living have a greater deal of awareness and stronger environmental convictions than people with low standards of living and education. This tendency for people to be more concerned with the environment when they are well-off can be analysed and understood in part by the issue of satisfaction of primary needs (sufficient food, safety, employment, etc.), which take precedence over any environmental concern. When basic needs are met, the situation becomes more favourable to climate engagement. In our two study sites, the less well-off are more concerned with the issue of security from terrorism and job security, which puts the issue of CC in the background.

In the end, in a context where scientists and public authorities call for an acceleration of the implementation of adaptation strategies concerning CC, it is necessary to take into account these political, economic and ideological 
considerations in order to better inform people and inspire them to take action.

\section{Acknowledgements}

The authors "thank" the Hauts-de-France Region, the Ministry of Higher Education and Research (CPER Climibio) and the European Regional Economic Development Fund (ERDF) for their financial support.

\section{References}

Adger, W. N., Barnett, J., Brown, K., Marshall, N., \& O'Brien, K. (2013). Cultural dimensions of climate change impacts and adaptation. Nature Climate Change, 3, 112-117. https://doi.org/10.1038/nclimate1666

Beck, U. (1992). Risk Society: Towards a New Modernity. London, Sage Publication.

Blennow, K., Persson, J., Tomé, M., \& Hanewinkel, M. (2012). Climate Change: Believing and Seeing Implies Adapting. PLOS ONE 7, e50182. https://doi.org/10.1371/journal.pone.0050182

Bozonnet, J. P. (2011). Inégalités environnementales et contre-récit climatique en Europe. 4ème Congrès de l'Association Française de Sociologie, Jul 2011, Grenoble, France.

Bréchon, P. (2014). Les valeurs des Européens et leur degré de polarisation politique. Politique européenne, 45(3), 26-59.

Bréchon, P., \& Gonthier, F. (Eds.). (2017). European Values. Leiden, Nederland: BRILL. https://doi.org/10.1163/9789004341067

Brink, E., \& Wamsler, C. (2018). Citizen engagement in climate adaptation surveyed: The role of values, worldviews, gender and place. Journal of Cleaner Production. https://doi.org/10.1016/j.jclepro.2018.10.164

Busca, D., \& Toutain, S. (2009). Analyse factorielle simple en sociologie: méthodes d'interprétation et études de cas. de Boeck, 259 p.

Chauvel, L. (2010). Le Destin des générations: structure sociale et cohortes en France du XXe siècle aux années 2010, Paris, PUF,432 p.

Combessie, J. (2007). Sondages, échantillons. Dans La méthode en sociologie, pp. 45-54, Paris: La Découverte.

Douglas, M., \& Wildavsky, A. (1983). Risk and Culture: An Essay on the Selection of Technological and Environmental Dangers. University of California Press, Berkeley/Los Angeles.

Dunlap, R. E., Van Liere, K. D., Mertig, A. G., \& Jones, R. E. (2000). New Trends in Measuring Environmental Attitudes: Measuring Endorsement of the New Ecological Paradigm: A Revised NEP Scale. Journal of Social Issues, 56, 425-442. https://doi.org/10.1111/0022-4537.00176

Ecklund, E. H., Scheitle, C. P., Peifer, J., \& Bolger, D. (2017). Examining Links Between Religion, Evolution Views, and Climate Change Skepticism. Environment and Behavior, 49, 985-1006. https://doi.org/10.1177/0013916516674246

Escofier, B., \& Pagès, J. (2008). Analyses factorielles simples et multiples: objectifs, méthodes et interprétations. Dunod, 2008, 4e éd., 318 p.

Eurobaromètre Spécial 313.b. (2009). Les attitudes des Européens vis-à-vis du changement climatique. Report, Publication: juillet 2009.

Geoghegan, H., \& Leyson, C. (2012). On climate change and cultural geography: farming on the Lizard Peninsula, Cornwall, UK. Climatic Change, 113, 55-66. https://doi.org/10.1007/s10584-012-0417-5

Giddens, A. (1994). Les Conséquences de la modernité. Paris, L'Harmattan.

Glaas, E., Neset, T. S., Kjellström, E., \& Almås, A. J. (2015). Increasing house owners adaptive capacity: Compliance between climate change risks and adaptation guidelines in Scandinavia. Urban Clim. https://doi.org/10.1016/j.uclim.2015.07.003.

Häkkinen, K., \& Akrami, N. (2014). Ideology and climate change denial. Personality and Individual Differences, 70, 62-65. https://doi.org/10.1016/j.paid.2014.06.030

Hegger, D. L. T., Mees, H. L. P., Driessen, P. P. J., \& Runhaar, H. A. C. (2017). The Roles of Residents in Climate Adaptation: A systematic review in the case of the Netherlands. Environ. Policy Gov., 27, 336-350. https://doi.org/10.1002/eet.1766

Hulme, M. (2009). Why We Disagree about Climate Change: Understanding Controversy, Inaction and Opportunity. Cambridge University Press. 
IFOP pour la Fondation Jean-Jaurès et Conspiracy Watch. (2017). Enquête sur le complotisme, décembre 2017, $147 \mathrm{p}$.

IPCC. (2018). Summary for Policymakers. In: Global warming of $1.5^{\circ} \mathrm{C}$. In V. Masson-Delmotte, P. Zhai, H. O. Pörtner, D. Roberts, J. Skea, P. R. Shukla, ... T. Waterfield (Eds.), An IPCC Special Report on the impacts of global warming of $1.5^{\circ} \mathrm{C}$ above pre-industrial levels and related global greenhouse gas emission pathways, in the context of strengthening the global response to the threat of climate change, sustainable development, and efforts to eradicate poverty (pp. 32). World Meteorological Organization, Geneva, Switzerland.

McCright, A. M., \& Dunlap, R. E. (2011). Cool dudes: The denial of climate change among conservative white males in the United States. Global Environmental Change, 21, 1163-1172. https://doi.org/10.1016/j.gloenvcha.2011.06.003

McCright, A. M., Marquart-Pyatt, S. T., Shwom, R. L., Brechin, S. R., \& Allen, S. (2016). Ideology, capitalism, and climate: Explaining public views about climate change in the United States. Energy Research \& Social Science, 21, 180-189. https://doi.org/10.1016/j.erss.2016.08.003

Michel-Guillou, E. (2014). La représentation sociale du changement climatique : enquête dans le sens commun, auprès de gestionnaires de l'eau. Les cahiers internationaux de psychologie sociale, 2014/4 Numéro 104, p. 647-669.

Möhler, K., Piet, G., \& Zaccai, E. (2015). Changement climatique et familles politiques en Europe. Courrier hebdomadaire du CRISP, 5-52. https://doi.org/10.3917/cris.2257.0005

Nickerson, R. S. (1998). Confirmation bias. A ubiquitous phenomenon in many guises. Rev. Gen. Psychol., 2 , $175-220$.

O'Brien, K. L. (2009). Do values subjectively define the limits to climate change adaptation? In I. Lorenzoni, K. L. O’Brien, \& W. N. Adger (Eds.), Adapting to Climate Change: Thresholds, Values, Governance (pp. 164180). Cambridge University Press, Cambridge. https://doi.org/10.1017/CBO9780511596667.011

O’Brien, K. L., \& Wolf, J. (2010). A values-based approach to vulnerability and adaptation to climate change. Wiley Interdiscip. Rev. Clim. Change, 1, 232-242. https://doi.org/10.1002/wcc.30

Persson, J., Sahlin, N.-E., \& Wallin, A. (2015). Climate change, values, and the cultural cognition thesis. Environmental Science \& Policy, 52, 1-5. https://doi.org/10.1016/j.envsci.2015.05.001

Pidgeon, N. (2012). Public understanding of, and attitudes to, climate change: UK and international perspectives and policy. Climate Policy, 12, S85-S106. https://doi.org/10.1080/14693062.2012.702982

Thompson, M., Ellis, R., \& Wildavsky, A. (1990). Cultural theory. Westview Press Inc, Oxford.

Wamsler, C. (2018). Mind the gap: The role of mindfulness in adapting to increasing risk and climate change. Sustainability Science, 13, 1121-1135. https://doi.org/10.1007/s11625-017-0524-3

Wilkinson, K. K. (2010). Climate's Salvation? Why and how American Evangelicals are engaging with climate change. Environment: Science and Policy for Sustainable Development, 52, 47-57. https://doi.org/10.1080/00139151003626822

Ziegler, A. (2017). Political orientation, environmental values, and climate change beliefs and attitudes: An empirical cross country analysis. Energy Economics, 63, 144-153. https://doi.org/10.1016/j.eneco.2017.01.022

\section{Notes}

Note 1. For easier reading, the acronym "CC" will replace the expression "climate change" in the body of the text.

Note 2. The new ecological paradigm (NEP) is an indicator of environmental values. It focuses on the limits of growth and the preservation of natural resources according to people's beliefs about nature (Dunlap et al., 2000). Starting from the idea that human societies have the capacity to upset the balance of nature, the NEP makes it possible to understand the way in which these societies perceive their impacts on the biosphere and the interactions that connect them. According to our ecological vision of the world, we act on the natural resources in a positive or negative way.

Note 3. Became Rassemblement National (National Rally) on the 1st of June, 2018. 
Note 4. Given the structure of the questionnaire and the size of the sample surveyed ( $n=202$ in Chauny and 233 in Lille), we did not perform any data adjustment. The adjustment postulates that, within each category, the non-respondents would have given the same type of answers as those who responded (Combessie, 2007). But in our questionnaire, multiple choices and many open questions make it difficult or impossible to validate this adjustment postulate.

Note 5 . From this question, the answers were recoded between 5 political groups: $1-2=$ far left; $3-4=$ left; $5=$ centre; 6-7-8 = right; 9-10 = far right.

Note 6. The economic standard of living has been calculated on the basis of the household income and the number of consumption units (CU) it contains: each household member is given a coefficient, the number of persons is thus converted into $\mathrm{CU}$. The Insee scale allocates $1 \mathrm{CU}$ for the first adult in the household, $0.5 \mathrm{CU}$ for other persons aged 14 or over and $0.3 \mathrm{CU}$ for children under 14 years of age. We thus calculated the income per $\mathrm{CU}$ and established three living standards: low (income per CU less than or equal to the poverty line, i.e. $€ 1015 /$ month), average (income per CU between $€ 1015$ and $€ 2000 /$ month) and favourable (more than $€ 2000 /$ month).

Note 7. Or KNN (K Nearest Neighbours), the imputed value being that of similar individuals.

Note 8 . The values of this group with all the others are very small, i.e. $\mathrm{Rv}=0.099$ (very different from 1 , maximum value reached when the link is absolute) and dimensionality $\mathrm{Lg}=0.6$ (very far from 5.45 within the group itself).

Note 9. Cos 2 with modality $>\cos 2$ mean of F1 or F2, that is $=0.163$ for the 1 st axis and 0.053 for the second one.

Note 10. Comparing this percentage of $25 \%$ of respondents who did not want to express their political orientation and the ratio of voters in the 2017 presidential election at the two study sites gives some indications: according to our survey in Chauny only $5 \%$ of respondents say that they are clearly and explicitly right-wing extremists, and $35 \%$ of respondents did not want to comment on their political affiliation. However, the Front National (FN) came in first in the second round of the 2017 presidential election with $51 \%$ of the vote against $49 \%$ for En Marche (EM). In Lille, only 1\% of respondents clearly declare themselves as sympathising with the extreme right and $17 \%$ of respondents did not wish to express their political position. The election results show that $78 \%$ of Lille voted for En Marche compared to $21 \%$ for the FN. In the light of these figures and trends, it can be hypothesised that people who do not want to express their views on politics tend to look to the extreme right without declaring this, especially in Chauny.

Note 11. These reports were collected at the end of the questionnaires when respondents were asked if they wanted to add anything (a comment, an idea, a critic, another subject...).

\section{Copyrights}

Copyright for this article is retained by the author(s), with first publication rights granted to the journal.

This is an open-access article distributed under the terms and conditions of the Creative Commons Attribution license (http://creativecommons.org/licenses/by/4.0/). 